\title{
Cognitive Support for Older People from Multimedia Options
}

\author{
P. Wright*, S. Belt, A. J. Soroka, D. T. Pham, S. Dimov, D. C. DeRoure, H. Petrie *Member, ISG
}

\begin{abstract}
If older users of multimedia displays could select among presentation options, would they choose display combinations that supported their performance? After three short touch-screen tasks which measured the perceptual and cognitive abilities of 50 older adults, they answered questions about a route on an online map that could be accompanied by written and/or spoken text. Half the participants saw animated routes; and they were less accurate answering questions than those who saw static routes but this did not affect people's multimedia choices which, although diverse, were systematic. Spoken text was more often selected by people who had lower scores on the spatial working memory task, than by the older adults with higher scores. This suggests that older people with cognitive limitations recognise ways in which multimedia information can be supportive.
\end{abstract}

\section{INTRODUCTION}

$\mathrm{T}$ HE potential value of modern information and communication technology for older people, and those who support them, is increasingly being recognised particularly the usefulness of informational websites [1]. Although the content of such sites may sometimes have begun as printed leaflets, digital media afford much richer communication options. Two of the features of digital documents that distinguish them from printed information are (a) that they can have audio, so text on screen can be spoken, and (b) the graphics can be animated. Research by educational psychologists has shown that the combination of listening while watching an animation is particularly effective in assisting understanding and remembering [2]. The present study examines whether this principle also applies in reading tasks where the text does not have to be remembered, and when the readers are much older than those usually taking part in educational research. There is evidence that interfaces which appeal to young adults are not necessarily those preferred by older people [3], [4].

Because it is known that older people often have memory problems [5], [6], an 'open book' reference task was chosen, and people only had to consult the information on screen in order to be able to answer the questions. This kind of reading activity has received relatively little

Manuscript received 30 April 2008. The authors acknowledge with thanks the support of an Economic and Social Research Council Award L328253011 as part of the P@CCIT (People at the Centre of Communication and Information Technologies) programme which was also supported by EPSRC and DTI.

P. Wright and S. Belt at the School of Psychology, Cardiff University, CF10 3AT, UK (phone: +44 02920 874730; fax: +44 02920 874858; email: wrightp1@ cardiff.ac.uk).

A. J. Soroka, D.T. Pham, S. Dimov at the Manufacturing Engineering Centre, Cardiff University, UK. (email SorokaAJ@ cardiff.ac.uk)

D. C. DeRoure at School of Electronics and Computer Science, Southampton University, SO171BJ, UK (email D.DeRoure@soton.ac.uk)

H. Petrie at Dept of Computer Science, University of York, York YO10 5DD, UK. (email petrie@cs.york.ac.uk). attention from researchers concerned with reading processes, although there is some educational research with students [7]. In contrast, researchers interested in human-computer interaction have explored how people navigate through digital documents in a range of contexts [e.g. 8]. Reference tasks, in which people seek answers to queries that they have, may be typical of the way computer resources such as the www are used by older people.

Reference tasks can vary in how precisely the target information is specified, and so in how much decisionmaking is involved [9]. On the one hand there are simple searches with almost no decision-making, for example wanting the phone number of a particular shop; other searches may have under-specified criteria such as wanting something to wear for a special occasion. The present research focus will be on simple reference tasks where the target is fully specified. Even within these simpler tasks there remains diversity because sometimes the answer may be found at a single location (e.g. if checking item availability at a store), but at other times it may be necessary to make comparisons across locations (e.g. comparing a price in two or more stores). Here memory processes become involved to a greater extent than in the single location search although, if forgotten, the information can be re-checked. So, as a reference task, it remains very different from learn-and-remember tasks.

An interface was created where people were able to select whether to listen while they read, or listen instead of reading, or listen while referring to a map that either had an animated route or highlighted a static version of the same route. Although it has been reported that people are less likely to choose to listen when engaged in reference activities than when following procedural instructions [10], the involvement of animated graphics in the present reference task might well change this, making listening a more helpful option.

It is known that diversity among peer groups increases with age [11] and that people vary in their multimedia preferences [12]. The present study explored whether the multimedia selections made by older people were related to sensory and/or cognitive factors associated with the ageing process rather than chronological age. Before engaging in the reference task, three sensory/cognitive abilities were assessed, all of which if impaired might be expected to increase the choice of spoken text: (a) fairly obviously, visual impairments are likely to increase the desire for spoken information. So the ability to search for and read information from the screen was assessed. (b) the ease of hearing and understanding the computer voice, coupled with the ability to remember what it said, is also likely to influence multimedia choices. So a short auditory digit span test was devised. (c) Visuo-spatial skills were 
assessed because in a simulated real-world task it has been found that visuo-spatial skills had significant impact on performance when people completed online fuel tax forms for trips taken by truck drivers [13]. Visuo-spatial skills have also been shown to predict differences among students on information search tasks [14], and technology use by older adults in Japan [15].

\section{METHOD}

\section{A. Participants}

50 adults were recruited by advertising in local papers for people up to 80 years to receive payment in return for giving us feedback on our talking computer. The ages of the volunteers ranged from 59-81, mean age 67.2.

\section{B. Materials and Tasks}

All materials were presented online via a 15 inch touchscreen display (Protouch), with a resolution of 1024 x 768, driven from a Dell Inspiron 4000 laptop running Windows 2000. The volume of an audio speaker adjacent to the screen was adjusted to suit each person at the start of the session.

Pretests were devised to be readily understood by people who might be unfamiliar with computers. Only the Verbal Short Term Memory task involved audio.

Visual Search. A name and address were shown at the top of the screen on the right and people were asked to locate this target in a 20 item phone list, then tap the seven digit phone number into an onscreen keypad (see Fig. 1) and check it was correct before continuing by tapping the OK button. There were eight trials, each having a different target and phone list.

\begin{tabular}{|c|c|c|c|c|}
\hline Sithers J. Waterloo Road & 4620788 & & & \\
\hline Sithers M. Beechwood Drive & 6304873 & \multicolumn{3}{|c|}{ 3) Dial the number for $M$ Skardon. } \\
\hline Sivell G. Greenway Road & 2146358 & & & \\
\hline Sivell R.E. Romilly Crescent & 3779688 & & & \\
\hline Sivori G.T. Bwlch Road & 9520534 & & & \\
\hline Sivyer I.G. Amethyst Road & 5687153 & & & \\
\hline Skagestad P. Baroness Place & 3428756 & & & \\
\hline Skamp A.P. Nora Street & 9642583 & \multicolumn{3}{|c|}{3462286} \\
\hline Skardon M. Queens Road & 3462286 & & \multirow{3}{*}{2} & \multirow{3}{*}{3} \\
\hline Skeats V.A. School Street & 4427001 & \multirow[t]{2}{*}{1} & & \\
\hline Skeavington R. Barberry Close & 7034055 & & & \\
\hline Skedgwell L.C. Ham Lane North & 1156782 & \multirow[t]{2}{*}{4} & \multirow[t]{2}{*}{5} & \multirow{2}{*}{6} \\
\hline Skehan D.M. Allerton Street & 8224996 & & & \\
\hline Skelding H.K. Lavernock Point & 3846214 & \multirow[t]{4}{*}{7} & \multirow{2}{*}{8} & \multirow{2}{*}{9} \\
\hline Skelding M.P. Summerhill Drive & 3266509 & & & \\
\hline Skellern L. Cherrytree Grove & 5067793 & & \multirow{2}{*}{0} & \\
\hline Skellon M.C. St Fagans Road & 3553468 & & & \\
\hline Skellon M.R. Stephenson Road & 3356242 & & & \\
\hline Skelly M.J. Theodora Street & 7953046 & \multirow[t]{2}{*}{ Cancel } & \multirow{2}{*}{\multicolumn{2}{|c|}{ OK }} \\
\hline Skelton H.W. Cornwall Street & 6597953 & & & \\
\hline
\end{tabular}

Fig. 1. The visual search task with addresses and phone numbers listed on left and the keypad on right.

Verbal Short Term Memory. This task was presented to participants as an opportunity to comment on the acceptability of the computer voice. People listened to a sequence of audio digits from the computer and then tapped this digit sequence into a row of buttons at the foot of the screen (see Fig. 2). As the buttons were clicked the digits appeared in the horizontal row of boxes in the middle of the screen. In total there were 12 digit sequences which varied in length from four to nine digits. Some came from a human female voice, others from a male synthetic voice (Microsoft SAM).

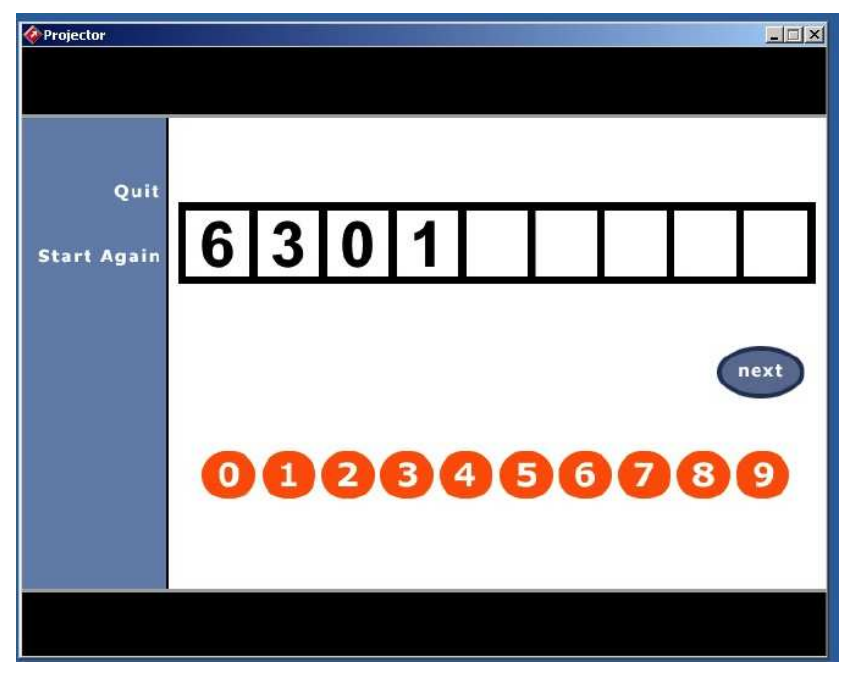

Fig. 2. Screen display in the Verbal Short Term Memory task.

Spatial Working Memory. This task was presented to participants as an opportunity for them to comment on the possible uses of animation, thereby reducing anxiety about a task which some people found difficult.

People viewed a graphic sequence in which a square of paper was folded three times and pierced by a pin. They then selected which of five graphics depicted the unfolded paper (see Fig. 3). There were six such problems three of which were animated and three were static. The sequences were derived from a web version of this task available from [16] who had based his version on measures of visualization ability included in cognitive tests developed by [17], [18].

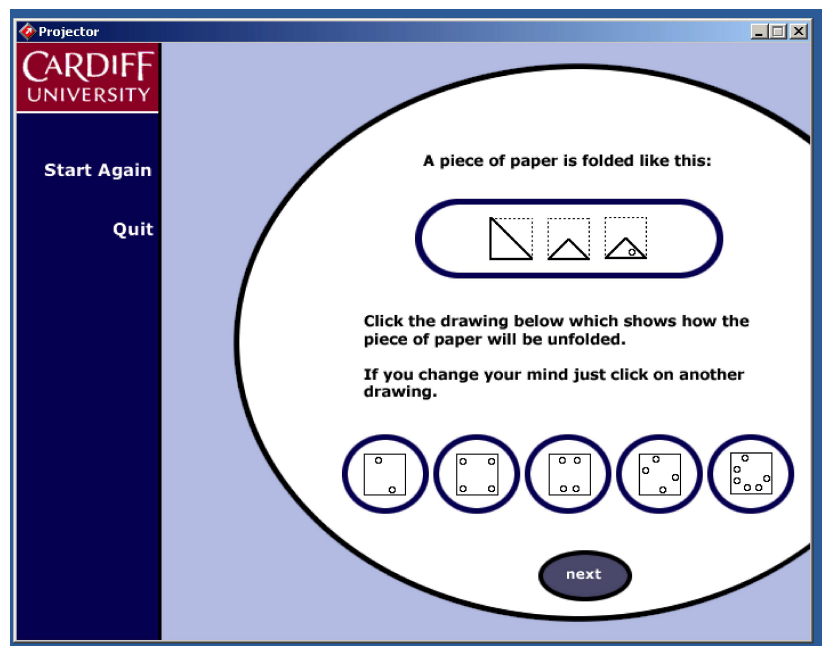

Fig. 3. Screen display in the Spatial Working Memory task showing the sequence of folds at the top, and the pin hole options when unfolded.

\section{Main task}

People answered multiple-choice questions about a road 
route between two locations in the UK which was shown on a map above the question (see Fig. 4). For all

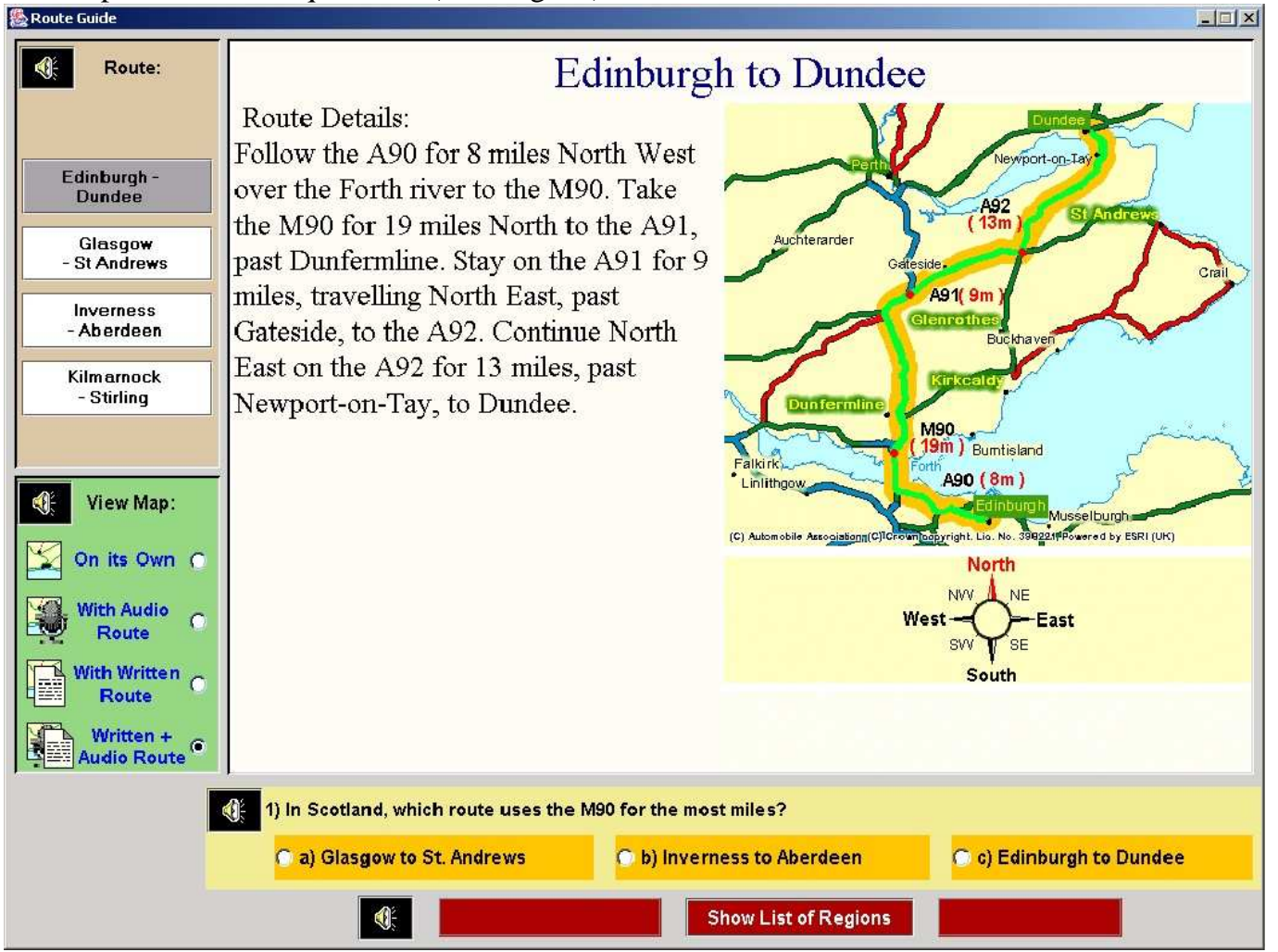

Fig. 4. Screen display in the main Routes task

whereas the other eight questions required comparing information from three routes.

By tapping buttons on the left of the screen, people chose to work with the map alone, or a map plus an auditory description of the route from a female synthetic voice (Microsoft SAM), or a map plus a written description of the route that was identical to the auditory information and shown to the left of the map, or all three information sources: map + written text + spoken text. People answered questions about 16 routes, continuing at their own pace with ample time to change their mind about the way information was presented. If selected, the text appeared all at once on the screen.

For half the participants the highlighted route on the map was animated for all 16 routes and progressed up the screen in synchrony with the voice reading the text, taking on average $32.5 \mathrm{~s}$ to complete the route. For the other participants the highlighted route between start and destination was shown already completed on a static map.

To cope with the non-standard pronunciation of some place names, the text-to-speech synthesizer did not read the text shown on screen but read a parallel text in which place names were spelt in the way that resulted in appropriate pronunciation.

All trials began with a question, to which participants responded by navigating to the appropriate map using the top beige panel on the left of the screen where regions within the UK were listed (e.g. Scotland, Wales, Midlands, etc). When one of these regions was tapped, the panel changed to show four pairs of starting points and destinations. This two-level hierarchic design was an attempt to comply with the suggestion that menu structures for older users should be shallow [19], while recognizing that an alphabetic listing of all 32 pairs of starting points and destinations would probably seem confusing, and would be contrary to the evidence that limiting the number of choices required at any one time can be helpful when adults have cognitive problems [20]. Other research has established that having navigation options remain visible alongside digital documents can help readers [21].

No route information was displayed in the centre of the screen until presentation options had been selected from the lower green panel on the left of the screen. The panel remained visible throughout the trial, so presentation options could be changed at any point. Selections did not carry over from one trial to the next but had to be made at the outset of every trial.

\section{RESULTS}

In a debriefing interview people said they found the touch-screen easy to use (mean rating 1.86 on a scale from $1=$ very easy to $7=$ very difficult). Across all 16 trials $78 \%$ of answers to the route questions were correct. There were no accuracy differences between men (mean 2.9 errors) and women (mean 2.8 errors). However, more errors were made when the routes were animated (mean 4.04, sd 2.58) than when they were not (mean 2.96, sd 1.5) $\left(\chi^{2}(1)=3.3\right.$, $\mathrm{p}<0.05$, one tailed). It was also noticed that the voice was more often selected (76.6\% trials) when the route was animated than when it was static ( $37.5 \%$ trials).

In the routes task, most people retained their chosen multimedia combination throughout the 16 trials and so 
could be classified by this choice. Table 1 summarises the distribution of dominant choices, and shows the diversity among these volunteers. However, the data from seven people were not included either for technical reasons or because their choices varied (4 had animated routes, 3 had static routes). Although the biggest single group (15 people) chose to work with the map alone, nearly twice as many (28) chose to work with the map plus some form of verbal support. Table 1 also shows that those selecting the addition of written text were more accurate $\left(\chi^{2}(1)=12.47\right.$, $\mathrm{p}<0.01)$.

Table I. Multimedia choices and performance on Routes

\begin{tabular}{|l|c|c|c|}
\hline $\begin{array}{l}\text { Multimedia } \\
\text { Chosen }\end{array}$ & N & Age & $\begin{array}{r}\text { Accuracy } \\
(\text { SD })\end{array}$ \\
\hline Map only & 15 & 67.2 & $11.4(2.4)$ \\
Map+Audio & 10 & 69.0 & $11.7(1.6)$ \\
Map+Text & 10 & 67.7 & $14.0(1.6)$ \\
Map+Aud+Txt & 8 & 64.6 & $14.0(2.2)$ \\
\hline
\end{tabular}

Of central concern in this study was how the pattern of choices depicted in Table I would relate to pretest performance. Table II summarises performance on the three pretests, and shows that although the group who chose map+audio had the lowest score on Visual Search, as might be expected, this was not the case for those choosing map+audio+text. Rather, it was people with the lowest Spatial Working Memory scores who were most likely to select audio.

Table II. Accuracy on each of the three pretests

\begin{tabular}{|l|c|c|c|}
\hline $\begin{array}{l}\text { Multimedia } \\
\text { Chosen }\end{array}$ & $\begin{array}{c}\text { Visual } \\
\text { Search }\end{array}$ & $\begin{array}{c}\text { Auditory } \\
\text { STM }\end{array}$ & $\begin{array}{c}\text { Spatial } \\
\text { WM }\end{array}$ \\
\hline Map only & 7.4 & 4.9 & 3.1 \\
Map+Audio & 6.3 & 4.3 & 1.6 \\
Map+Text & 7.9 & 4.0 & 2.9 \\
Map+Aud+Txt & 7.7 & 4.9 & 1.9 \\
\hline
\end{tabular}

Of the 15 people with good scores on the Spatial Working Memory task (having four or more of the six items correct) only one person chose to listen, whereas of the 24 people who scored two or less correct on the Spatial task, ten chose to listen $\left(\chi^{2}(1)=3.3, \mathrm{p}<0.05\right)$.

\section{DISCUSSION}

These older participants found the touch-screen computer easy to use and most of them readily agreed to return for a second session if invited (a few had health problems). Because these volunteers were a self-selected sample, who therefore can be assumed to have a fairly positive attitude towards computer technology, no claims about the generality of this observation are appropriate. Nevertheless, their interactive experience while taking part in this study, with no keyboard involved, would most likely have been very different from any previous experience with using computers they might have had.

The slightly less accurate performance with the animated routes may have reflected pacing problems.
Breaking the route into shorter segments which people could move between at their own pace would have been one way of having the advantages of animation directing the viewer's attention in synchrony with the voice without the disadvantage of the viewer needing to keep pace with the route's progress up the screen. This suggests possible boundary conditions to the multimedia principles arising from educational research [2]. That literature predicts enhanced performance from combining animation and audio, but the educational research has often involved students studying for a memory test. In contrast, the present study was more akin to an open-book reading task where information only has to be consulted rather than memorized. Both cognitive demands and available resources may be critical factors determining the effects of multimedia combinations. In a study of older people using printed leaflets, it has been found that older people can be impaired by graphics that have no detrimental effects on younger adults [22].

The importance of knowing the boundary conditions of research findings is again highlighted when the present findings are compared with those of [23] where undergraduates learned a procedural task of how to bandage a hand. That study reported no advantage for animation (a video) over text-plus-graphics, although the video was better than either just the text or just the static graphics. Again both the task and the participants differed from the present study. So simplistic advice based on single studies seems unlikely to be useful in relation to multimedia combinations. Instead a task taxonomy in terms of processing resources required to do the task (memory demands were small in the present study), and other content and contextual factors, would be an advantage for knowing how best to provide multimedia information to specific audiences. It is already known that people who do not find reading easy, and people who are not native speakers of the language of the text on screen, are more likely to select spoken text when following instructions from the screen [24].

The greater accuracy of those people who chose written text is open to several interpretations. It might be the case that the text was a supportive adjunct in this task, or it could be that people who felt comfortable reading the text on screen were visually better able to cope with the map. If they were better readers for sensory reasons this would have been expected to show in performance on the Visual Search pretest. Table 1 suggests that there may have been such a tendency but it was not statistically significant. This issue could be pursued either with a larger sample or with a different measure of ability to read from the screen, but it seems scarcely worth establishing that people with difficulty reading from the screen are unlikely to choose support from written text.

The main finding of interest in this study is that the audio was most frequently chosen by those older people who had problems doing the Spatial Working Memory task. It is possible that this may relate to a difference in cognitive styles that some researchers have referred to as the distinction between imagers and verbalisers [25]. If 
people with low Spatial Working Memory tend to be verbalisers, then listening while viewing could help them integrate the two information sources; whereas reading the text either before or after viewing the map leaves them with a difficult integration task if they cannot easily remember the map.

It was noted that for most people the multimedia choices made on the routes task remained consistent across trials. This was unexpected. It had been thought that questions involving the comparison of several routes might change people's multimedia choices. Elsewhere it has been noted that people's preferences for multimedia combinations are likely to vary across tasks [10]. When the same group of older people did seven different tasks across two sessions, fewer than one third of these participants consistently chose to listen, or not listen, to a voice. This suggests that in general people are responding to the information processing resources required by specific tasks rather than classifying themselves as listeners or readers. Perhaps in the present routes task the increment in cognitive demands when more than one route needed to be consulted may have been too small to influence people's multimedia choices. Not only could people check back if they forgot information but, for questions such as Which of routes $A$, $B, C$ was the longest? they need only remember the current answer after each comparison. So memory demands were small.

\section{IMPLICATIONS}

Accommodating diversity by letting people select among multimedia options would appear to be a preferable alternative to providing a 'best guess' combination of modalities for the age group concerned. Indeed a strong implication of the present findings is that people, older people in particular, would benefit from having easy ways of combining or dispensing with information in specific modalities. This accords with the proposal that an increase is needed in "polite computing" that respects user choice and offers users relevant helpful alternatives [26]. It is true that many modern applications (e.g. word processors and email) offer users ways of tailoring the interface to their personal liking; but these options may lie buried several layers deep in a menu structure that requires people to distinguish at the outset between an item called Preferences and another called Customize. It is likely to be helpful for older people if some options, in particular modality options, are much more accessible.

This paper has deliberately not reported time data because the authors recognize that older people may not have efficiency as their highest priority. Even in studies where younger adults collaborated with a computer either through speech or written text, on tasks such as finding a restaurant or planning a trip, it was found that the spoken interactions resulted in longer times to solve the problems but in a more collaborative interaction [27]. There is evidence from focus groups that older adults tend to base their decisions about using computers more on the benefits they anticipate than on any cost factors, which could include time spent on an interaction. One of the privileges of growing older is that there can be time to take the scenic route, to do things in whichever way feels most comfortable, rather than assuming there is a need to use the fastest method. This fits well with the recent developments within research on human-computer interaction, where there is a growing tendency to look beyond the usability of the interface and to consider more broadly the users' experience [28]. Creating multimedia interfaces that can easily be modified by users themselves to accommodate changing priorities across the lifespan, or across cognitive profiles within peer groups, would seem to be an important means of enhancing universal access.

\section{REFERENCES}

[1] S. Lauriks, A. Reinersmann, H. G. Van der Roest, F. J. M. Meilard, R. J. Davies, F. Moelaert, M. D. Mulvenna, C. D. Nugent, R. M. Droes, "Review of ICT-based services for identified unmet needs in people with dementis," Ageing Research Reviews, vol. 6, pp. 223 246, 2007.

[2] R. E. Mayer and R. Moreno, "Animation as an aid to multimedia learning," Educational Psychology Review, vol. 14, pp. 87-99, 2002.

[3] P. Wright, S. Belt, C. John, "Fancy graphics can deter older users: a comparison of two interfaces for exploring healthy lifestyle options," in People and Computers 17: Designing for Society, E. O'Neill, P.Palanque, and P. Johnson Eds. London: Springer-Verlag, 2003, pp. 315-325.

[4] A. Dickinson, A. F. Newell, M. J. Smith, and R. Hill, "Introducing the internet to the over-60s: developing an email system for older novice computer users," Interacting with Computers, vol. 17, pp. 621-642, 2006.

[5] E. A. Maylor, "Age-related changes in memory," in The Cambridge Handbook of Age and Ageing, M. L. Johnson, Ed. Cambridge, UK: Cambridge University Press, 2005, Ch. 3.3, pp. 200-208.

[6] R. A. Dixon, T. B. Rust, S. E. Feltmate, S. K. See, "Memory and aging: selected research directions and application issues," Canadian Psychology, vol. 48, pp. 67-76, 2007.

[7] J-F. Rouet, "What was I looking for? The influence of task specificity and prior knowledge on students' search strategies in hypertext," Interacting with Computers, vol. 15, pp. 409-428, 2003.

[8] M. Zeifle, U. Schroeder, J. Strenk and T. Michel, "How younger and older adults master the usage of hyperlinks in small screen devices," in Proc. ACM Sig CHI 2007, San Jose, California, pp. 307-316.

[9] P. Wright, "Hypertext as an interface for learners: some human factors issues," in D. H. Jonassen and H. Mandl, Eds. Designing Hypermedia for Learning, New York: Springer-Verlag, ch. 10, pp. 169-184, 1989.

[10] P. Wright, D. T. Pham, S. S. Dimov, D. C. DeRoure, and H. Petrie, "Spoken and written language in adaptable multimedia documents" in End of Award Report to ESRC, 2005. ref: L328253011.

[11] F. Blanchard-Fields, and T. M. Hess, Perspectives on Cognitive Change in Adulthood and Aging. New York: McGraw-Hill, 1996.

[12] P. Wright, "Talking computers and diversity in older audiences," Gerontechnology, vol. 4, pp. 187-189, 2006.

[13] S. J. Czaja, J. Sharit, S. Nair, and M. Rupert, "Understanding sources of user variability in computer-based data entry performance," Behaviour and Information Technology, vol. 17, pp 282-293, 1998.

[14] R. E. Downing, J. L. Moore, S. W. Brown, "The effects and interaction of spatial visualization and domain expertise on information seeking," Computers in Human Behavior, vol. 21, pp. 195-209, 2005.

[15] H. Umemuro, "Computer attitudes, cognitive abilities, and technology usage among older Japanese adults," Gerontechnology, vol. 3, pp. 64-76, 2004.

[16] K. Norman, Paper folding test. [Online]. Available: http://lap.umd.edu/v22

[17] R. B. Ekstrom, J. W. French, and H. H. Harman, "Manual for Kit of Factor Referenced Cognitive Tests." Princeton, NJ: Educational Testing Service, 1976. 
[18] R. B. Ekstrom, J. W. French, and H. H. Harman, "Cognitive factors: their identification and replication," Multivariate Behavioural Research Monographs, vol 79, pp. 3-84, 1979.

[19] D. Freudenthal, "Age differences in the performance of information retrieval tasks," Behaviour and Information Technology, vol. 20, pp. 9-22, 2001.

[20] E. Freeman, L. Clare, N. Savitch, L. Royan, R. Litherland, M. Lindsay, "Improving website accessibility for people with early stage dementia: a preliminary investigation," Aging and Mental Health, vol. 9, pp. 442-448, 2005.

[21] D. R. Danielson, "Web navigation and the behavioural effects of constantly visible site maps," Interacting with Computers, vol. 14, 601-618, 2002.

[22] J. Griffin and P. Wright, "Older readers can be distracted by embellishing graphics in text," European Journal of Cognitive Psychology, to be published.

[23] I. C. Michas and D. Berry, "Learning a procedural task: effectiveness of multimedia presentations," Applied Cognitive Psychology, vol. 14, pp. 555-575, 2000.

[24] A. J. Soroka, P. Wright, S. Belt, D. T. Pham, S. S. Dimov, D. DeRoure, and H. Petrie, "User choices for modalities of instructional information," in Proc $4^{\text {th }}$ International IEEE Conference on Industrial Informatics, INDIN'06, Singapore, August 2006, pp. 16-18.

[25] M. Graff, "Individual differences in hypertext browsing," Behaviour and Information Technology, vol. 24, pp. 93-99, 2005.

[26] B. Whitworth, "Polite computing," Behaviour and Information Technology, vol. 24, pp. 353-363, 2005.

[27] L. Le Bigot, P. Terrier, V. Amiel, G. Poulain, E. Jamet, J-F. Rouet, "Effect of modality on collaboration with a dialogue system," Int. J. Human-Computer Studies, vol. 65, pp. 983-991, 2007.

[28] A-S. Melenhorst, W. A. Rogers, and D.G. Bouwhuis, "Older adults' motivated choice for technological innovation: evidence for benefit driven selectivity, " Psychology and Aging, vol. 21, pp. $555-575,2006$. 